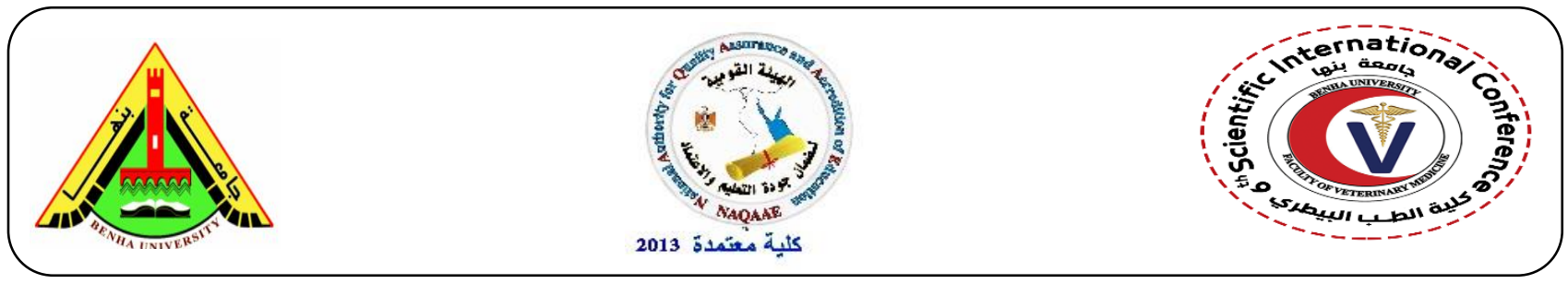

\title{
The potential anticancer effect of [Cadmium-N Acetyl cysteine] as novel drug therapy for mammary cancer induced by Di Methyl Benzene Anthanthrene in rats
}

\author{
Omayma A.R. AbouZaid ${ }^{1}$, Eman Noaman², Shaimaa abdel-Ati' ${ }^{1}$, Gehad Genidy Mohamed ${ }^{3}$. \\ ${ }^{1}$ Biochemistry Department, Faculty of Vet. Med. Moshtohor, Benha University, Egypt. \\ ${ }^{2}$ Radiation Biology Department, National Center for Radiation Research and Technology (NCRRT), \\ Atomic Energy Authority, Egypt. \\ ${ }^{3}$ Professor of Inorganic Chemistry, Faculty of Science Cairo University.
}

\section{A B S T R A C T}

The discovery of Cisplatin triggered the development of novel drugs containing other metals. Extremely diverse structural Chemistry and interaction of metal with ligand resulted in exploration of novel metal complexes with drug potential. The present work carried on 80 female rats which divided into four groups, after 12 weeks the mammary tumor appeared the possible anti-cancer effect of (Cadmium-N Acetyl Cysteine) which has been synthesized and study its effect on (Cd44, Cyclin D1, p21, caspase3, caspase 9 and cell cycle) were investigated on bearing solid mammary tumor induced by DMBA in rats.

key words: Metal complex- CD44-Cyclin D1-Caspase-ligand.

(http://www.bvmj.bu.edu.eg)

(BVMJ-34(3): 232-245, 2018)

\section{INTRODUCTION}

Breast cancer is the second most common cancer worldwide, the fifth most common cause of cancer death, and the leading cause of cancer death in women. The global burden of breast cancer exceeds all other cancers, and the incidence rates of breast cancer are increasing (Jemal et al.,2011).

7,12-dimethylbenz[a]anthracene (DMBA) is a potent organ specific pro-carcinogen, mediates carcinogenesis by causing DNA damage and inducing chronic inflammation. Also excessive generation of reactive oxygen species (ROS) that occur during metabolic activation of DMBA causes oxidative DNA damage, contributing to neoplastic transformation (Miyata et al., 2001). Although many anticancer drugs have been used to treat cancer, they have some limitations, such as side effects, tumor specificity, and tumor cell resistance. Inorganic chemistry offers many opportunities for medicinal chemistry, and the discovery of metal-based drugs has moved on 
from chance discovery to rational drug design. Drugs containing metals over many advantages over traditional organic compounds.

Firstly, more diverse coordination number and geometries are available compared carbon-based chemistry, compounds may be charged allowing interaction of oppositely charged biomolecules such as negatively charged DNA. Interaction with cellular components may also be facilitated by ligand exchange or equation processes. Finally, advantage may be taken of properties displayed by metals which are not found in biology (Frezza et al., 2010). Metal-ions based compounds have the abilities to coordinate ligands in a three-dimensional configuration (Simon ,2007), and provide suitable environment for various molecular structures that confer different geometries and kinetic properties that cannot be recognized by carbon-based chemical drugs (Cohen,2007).

In aqueous solution, metal ions exist as positively charged species. Depending on the existing coordination environment, the charge can be modified to generate species that can be cationic, anionic or neutral (Haas and Franz ,2009) •

The presence of urinary cadmium in $5 \%$ of the us population demonstrates the need for more researches that address the role of cadmium in human health (Zhukalin et al.,2007). Interestingly the human mammary gland also contains high concentrations of cadmium that mimics the effects of estradiol and might play a putative role in the etiology of the breast cancer (Brama et al., 2007).Acetylcysteine is the $N$-acetyl derivative of the amino acid L-cysteine, and is a precursor in the formation of the antioxidant glutathione in the body. Thiol (sulfhydryl) group confers antioxidant effects and can reduce free. The $\mathrm{O} / \mathrm{N}$ atoms in the side chains of amino acids can be potential binding site for metal ions depending on the position of the donor atoms and the hard-soft character of the metal ions. Taking into account the soft character of cadmium (II) a negligible effect of $\mathrm{O}$ donor side chains can be expected, while the $\mathrm{N}$ donor atoms may have an enhanced ability to take part in the complex formation process the sulfur atom with its soft character can be an important binding site for cadmium (II). In the present work of this thesis I investigated dysregulation of the cell cycle engine in breast cancer aimed at identification of new prognosticators and therapeutic targets.

Aim of this work to study the effect of cadmium $-\mathrm{N}$ acetyl cysteine synthesized complex on caspases 3,9, p21, cyclin D1, regulation of cell cycle and immune response of CD44 in tumor bearing rats.

\section{2-MATERIALS AND METHODS}

2.1-Chemicals: N-Acetyl Cysteine purchased from (Sigma, USA). N-acetyl cysteine, [ cadmium chlorides] was purchase from (Sigma, USA). Ethanol, ammonia from Egyptian company for chemicals).

2.2. Preparations and Measurements of [ $\mathrm{N}$ Acetyl cysteine Cadmium]. Mixed metal and ligand was synthesized and characterized by NMR and IR.

2.3. LD 50 calculation: Random numbers of female rats weighting $40 \mathrm{mg}$ are housed in laboratory and administrated different doses of complex orally. And for calculation safe dose,30 rats divided into three groups. each group containing 10 rats, $1^{\text {st }}$ group administrated $18 \mathrm{mg}, 2^{\text {nd }}$ administrated 16 $\mathrm{mg}, 3^{\text {rd }}$ administrated $12 \mathrm{mg}$, all doses dissolved in distilled water and the incidence of mortality recorded. So, the expected dose is $12 \mathrm{mg}$ as shown in table $(1,2)$. 
2.4. Dose of Induction of mammary tumor: $1 \mathrm{~g}$ of DMBA was dissolved in $80 \mathrm{ml}$ olive oil, each rat administrated 1 morally at the onset of the experiment (Gallo et al., 2001).

\subsection{Experimental design}

80 Female rats divided into 4 groups (20 each) as shown:

- Group (1): control group, 20 female rats not treated with anything and act as control(-ve).

- Group (2): complex group, 20 female rats treated only with complex at a dose of $12 \mathrm{mg}$ $/ \mathrm{kg}$ three times in a week for 12 weeks.

- Group (3): DMBA female rats. Carrying solid tumor after 12 weeks.

- Group (4): (DMBA+complex): 20 female rats carried the mammary tumor, administrated complex orally at dose $12 \mathrm{mg}$ $/ \mathrm{kg}$ three times for a week until the end of experiment after three months. 3.Tissue sampling:

After animals were anaesthetized mammary tissue of each animal were dissected out, washed, and dried after 21 weeks from the beginning of experiment, and divided into two parts, part of them was homogenate and samples were prepared in icecold phosphate buffer (0.1 M, PH7.4) using apotter - Elvehjem homogenizer to give a $10 \%$ homogenate which were used for determination of caspase 3 and caspase9, p21, CD44. Cyclin D, and cell cycle.

3.1. Preparation of tissue suspension: Fresh tissue specimens were transported to the laboratory in isotonic saline and prepared according to (Tribukait, 1984) as follow:

-1-The material was washed with isotone tris EDTA buffer, $3.029 \mathrm{~g}$ of $0.1 \mathrm{M}$ tris (hydroxy methylamino methane, $1.022 \mathrm{~g}$ of $0.07 \mathrm{M}$ sodium chloride (ADWIC) and 0.47 gm of 0.005 M EDTA.
-2- They were dissolved in $250 \mathrm{ml}$ of distilled water and then adjust the $\mathrm{PH}$ at 7.5 by using 1N HCL.

-3-Then, the cell suspension was centrifuged at $1800 \mathrm{rpm}$ for 10 mins., where upon the supernatant was aspirated. If they were macroscopically contaminated with blood, it was then subjected to hemolysis with filtered tap water for 10 mins.

-4- After centrifugation and aspiration of the supernatant the cell is fixed in ice-cold 96$100 \%$ ethanol in approximately $1 \mathrm{ml}$ for each sample. These fixed cells can be stored indefinitely in a refrigerator and can also be mailed without running the sample.

\subsection{Fixation of cells:}

- Fixation with ice cold absolute alcohol $1 \mathrm{ml}$ for each tube and preserved in $+4 \mathrm{c}$ forever until analysis.

\subsection{Staining method:}

- This technique is applicable where the fluorochrome is directly linked to the primary antibody by FITC conjugates.

\section{Statistical Analysis}

- The procedures were performed by using the Statistical Package for the Social Sciences (SPSS 17) statistical package (SPSS, Inc., Chicago, IL, USA) (Milton et al., 2011).

\section{RESULTS:}

Table (3) and (Fig.3-26) represent (CD44, P21, Cyclin D1, Cas-3, Cas-9 and cell cycle) activities in mammary tissue in all rats studied groups.CD44, P21.Cyclin D1, Cas-3, Cas-9 activities in mammary tissue showed no change occurred in control group and complex treated rats. Meanwhile, CD44, P21, Cyclin D1) activities in mammary tissue in DMBA group showed highly significant increase compared to control group. while, Cas-3 and Cas-9 showed significant decrease in DMBA group compared to control group. While, the 
data revealed significant increase in CD44, P21, Cyclin D1activities in mammary tissue in (DMBA+ complex) group compared to control rats, and highly significant increase in Cas3 and Cas-9 expression activities in (DMBA + complex) group compared to control groups. In cell cycle expression, complex induce marked changes in the cell cycle profile of DMBA rats. The finding

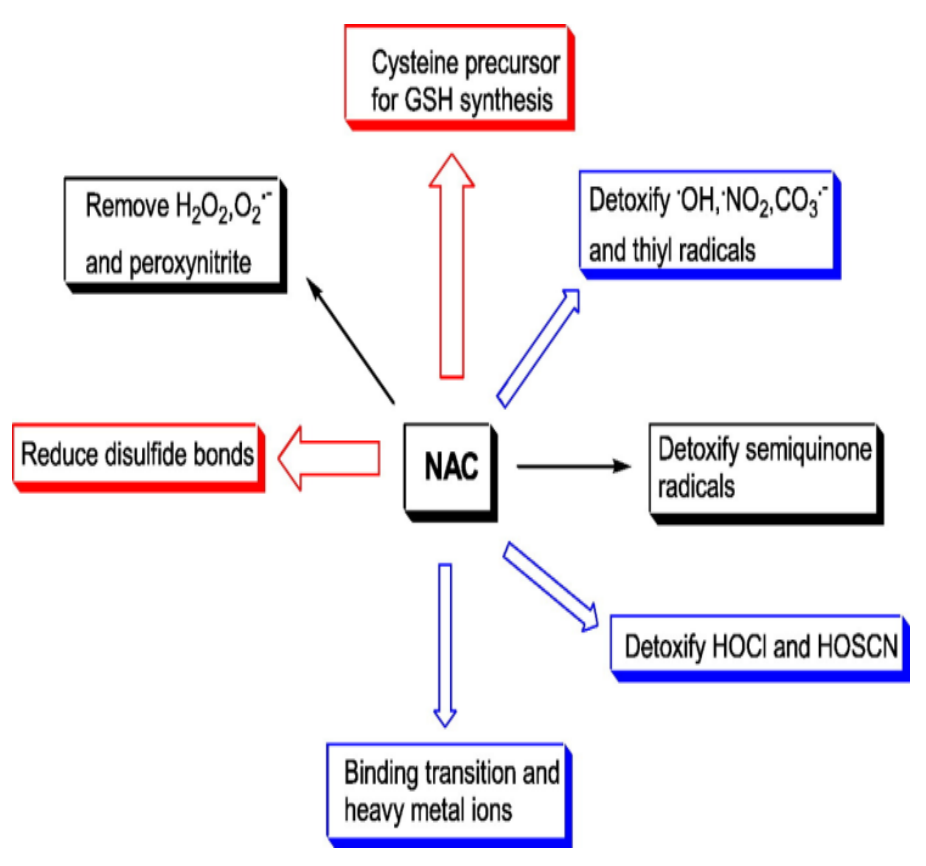

Fig.1. Chemical structure of N Acetyl Cysteine showed that obtains decrease proportion of cells in G0 \G1 phase in comparison with control. While, DMBA causes significant decrease G0 \G1 phase and significant in increase in $\mathrm{S}$ phase in comparison with control rats. Meanwhile after treatment the complex modifying the cycle and cause arrest in $S$ phase as shown in table (1) and figure (12).

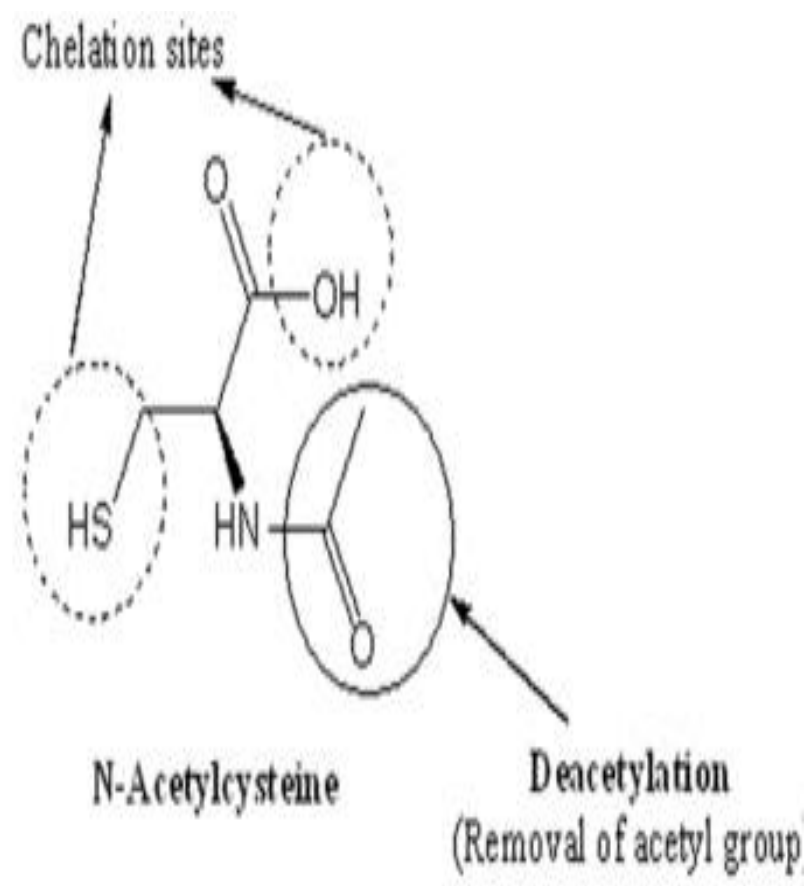

Fig. 2. Targets of N Acetyl Cysteine. 
1-Effect of complex on CD44 expression gene in normal and DMBA treated rats.

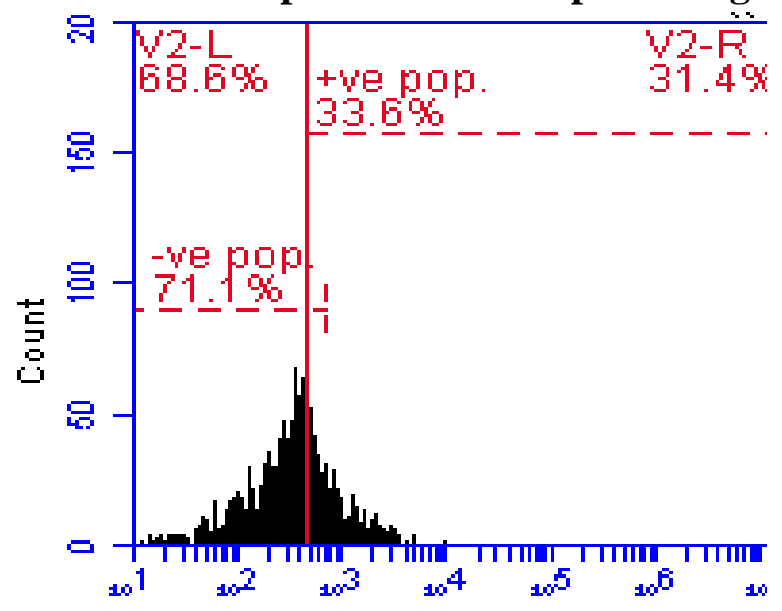

Fig.3.Group.1. Control

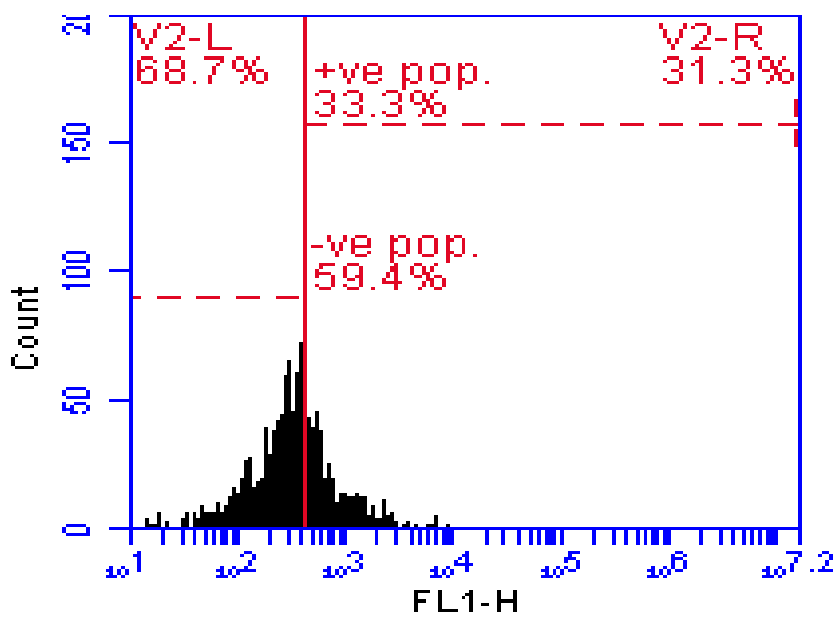

Fig.4. Group.2. Complex

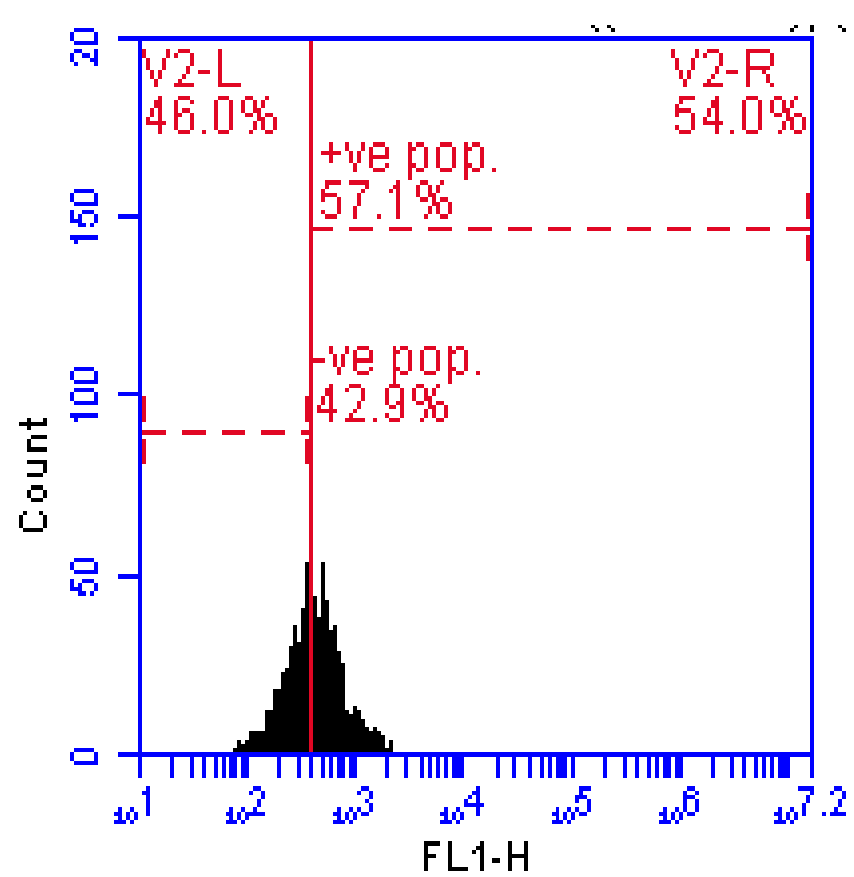

Fig.6. Group.4. DMBA + Complex 
The potential anticancer effect of [Cadmium-N Acetyl cysteine] as novel drug therapy for mammary cancer induced by Di Methyl Benzene Anthanthrene in rats

2-Effect of complex on p21 expression gene in normal and DMBA treated rats.

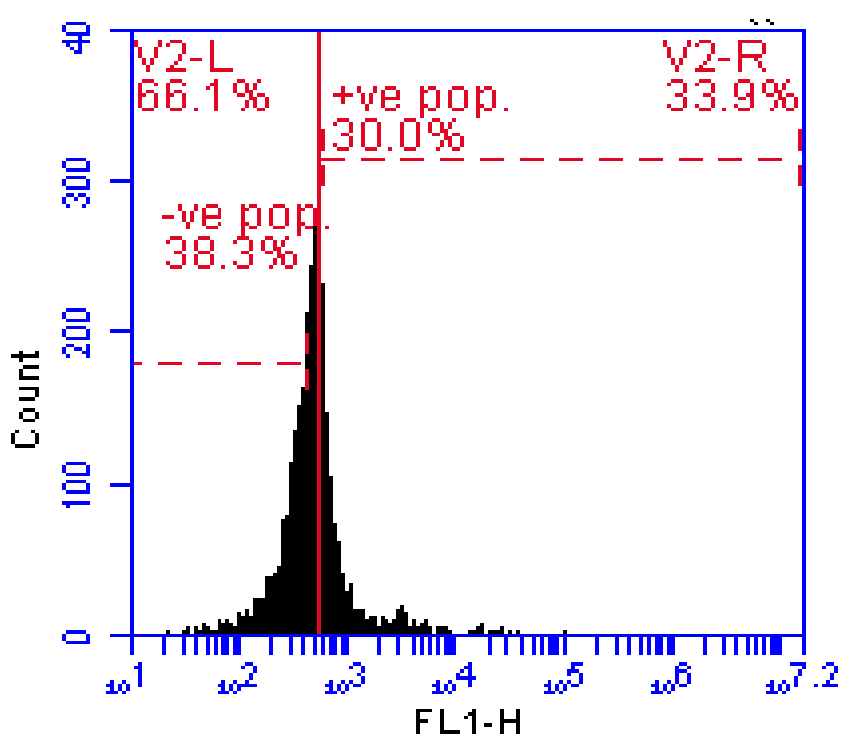

Fig.7.Group.1. Control Fig.

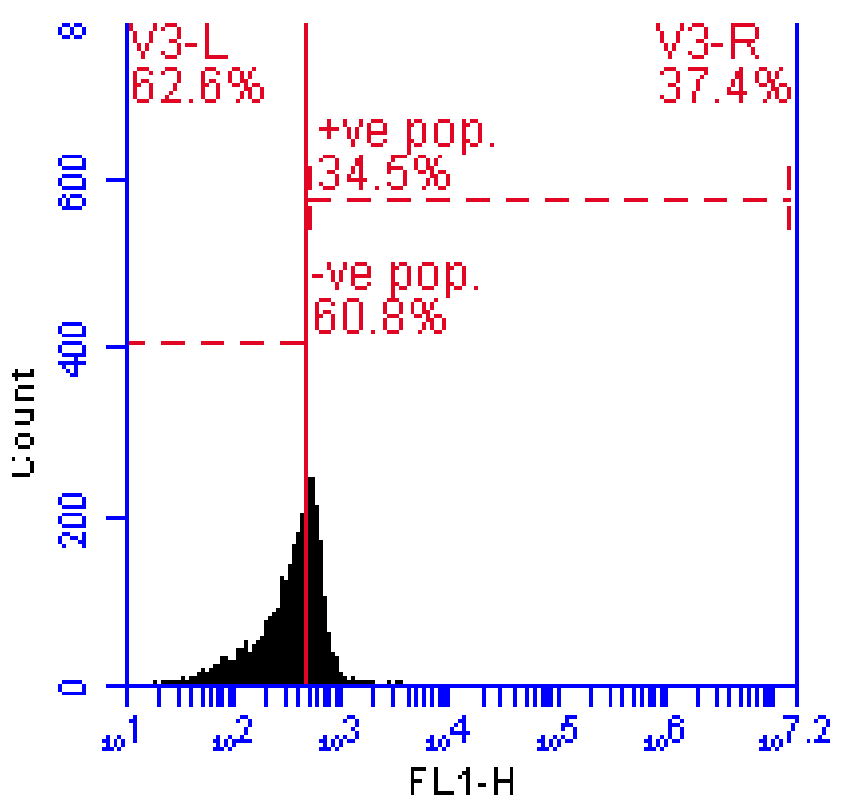

Fig.9.Group.3. DMBA

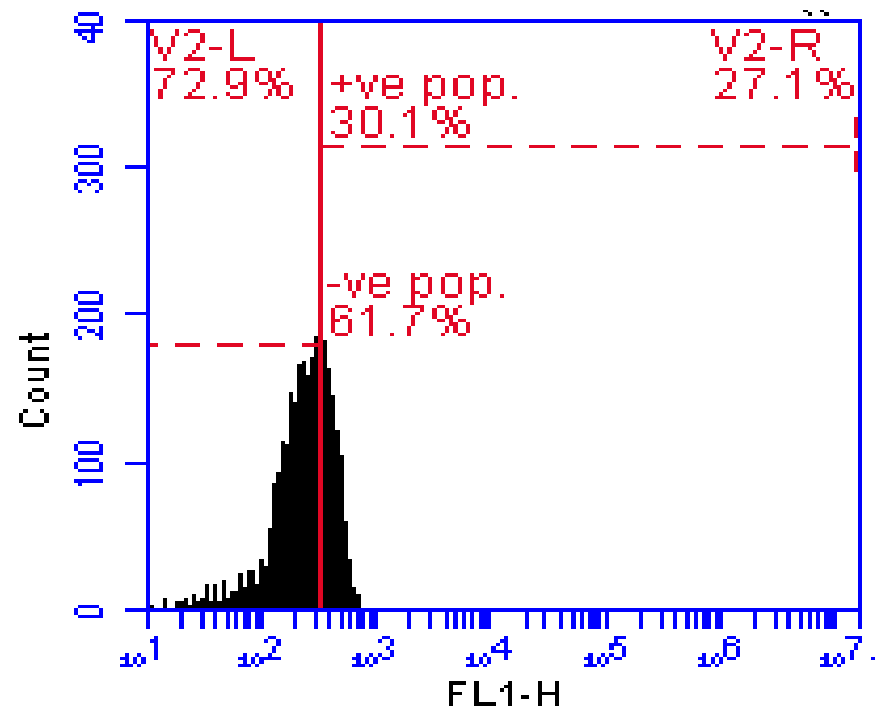

Fig.8. Group.2. Complex

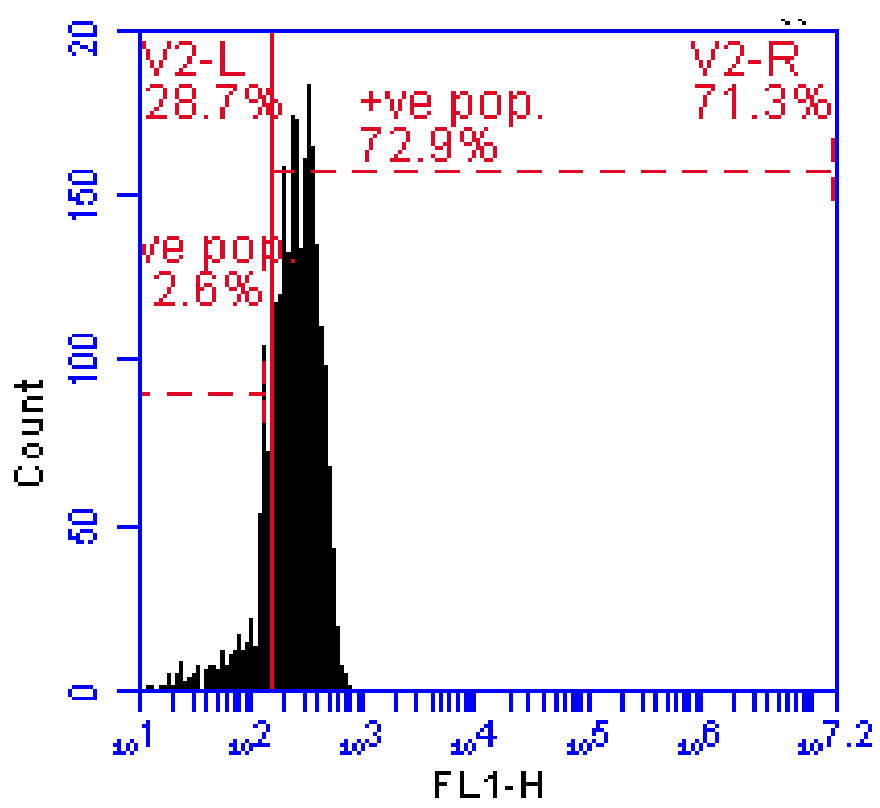

Fig.10.Group.4. Complex + DMBA 
3-Effect of complex on cyclin D1 on normal and DMBA tumor rat.

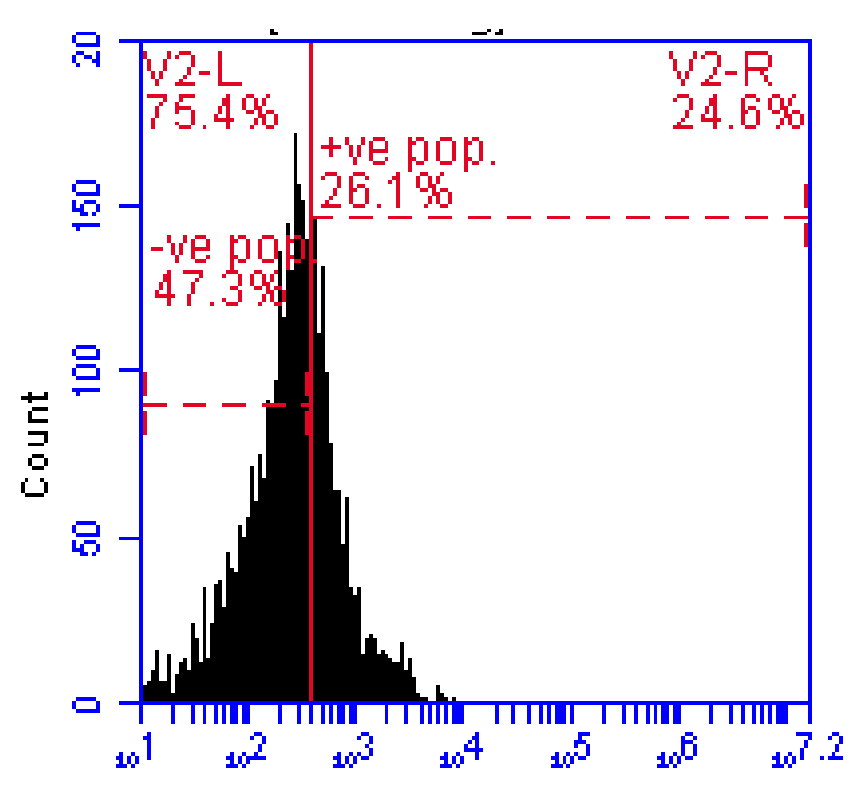

Fig. 11. group.1. control group

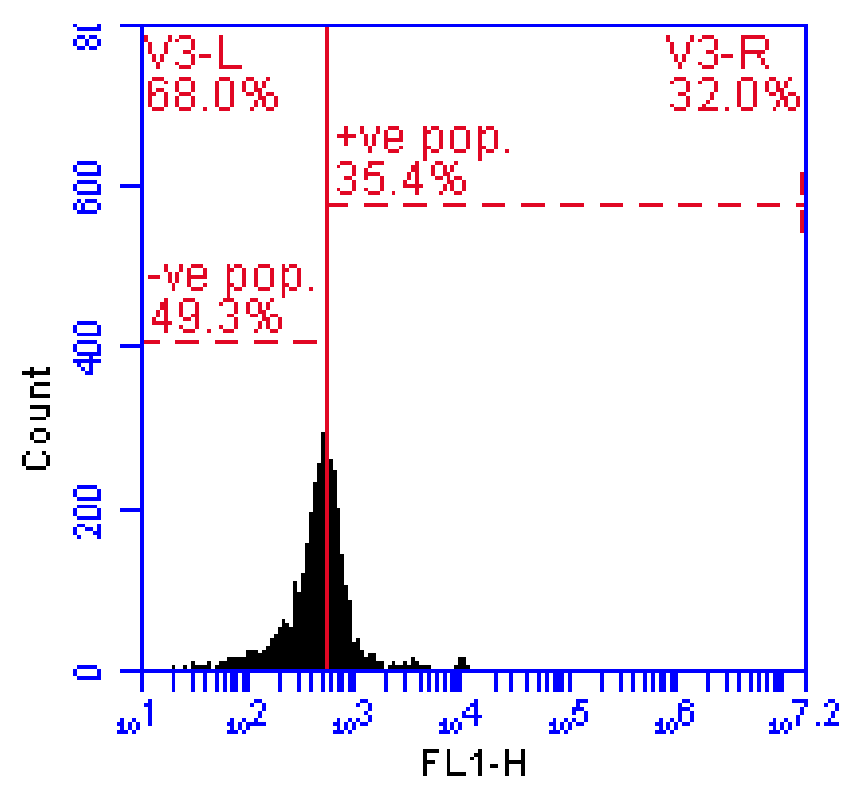

Fig. 13. group. 3. DMBA group

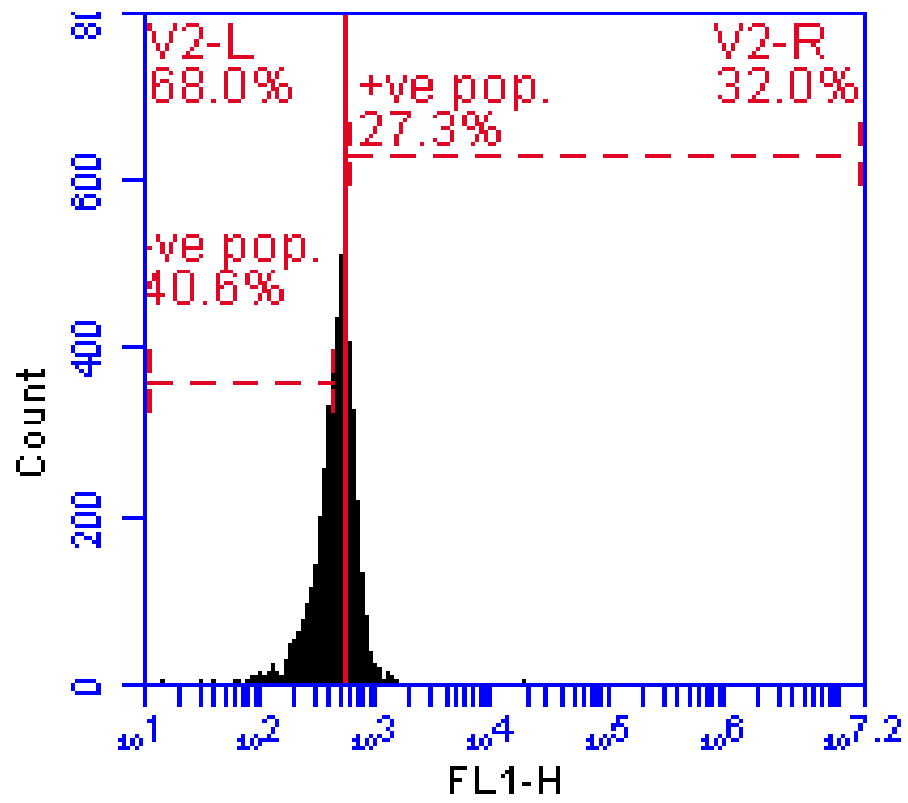

Fig. 12. Group. 2. Complex group

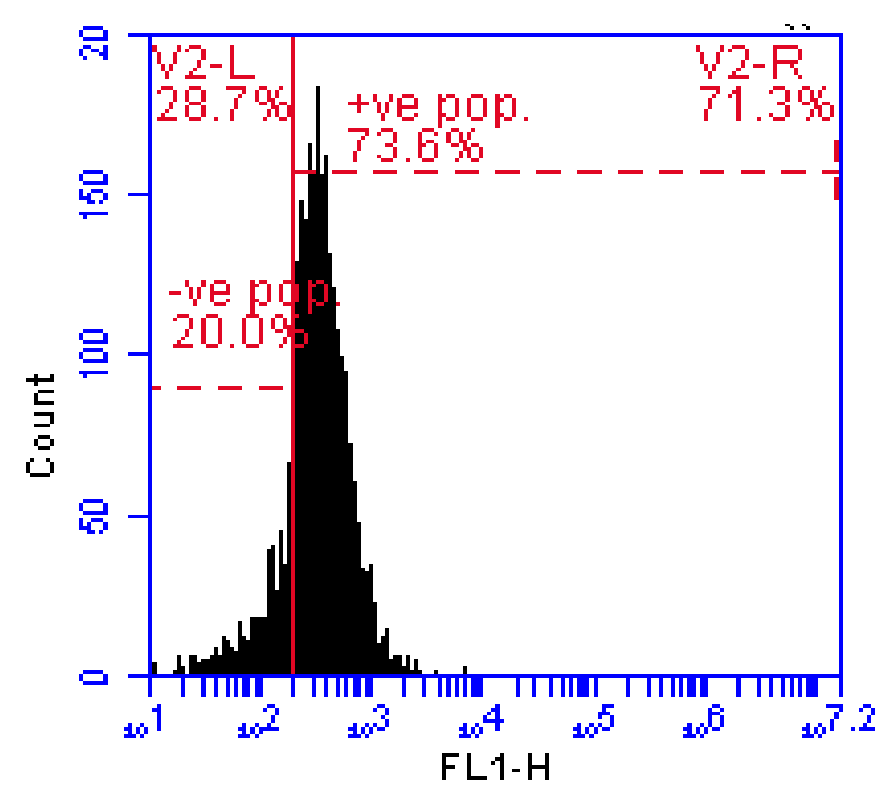

Fig.14.group.4. DMBA + complex 


\section{4-Effect of complex on cas3 activity expressions on normal and DMBA rat}

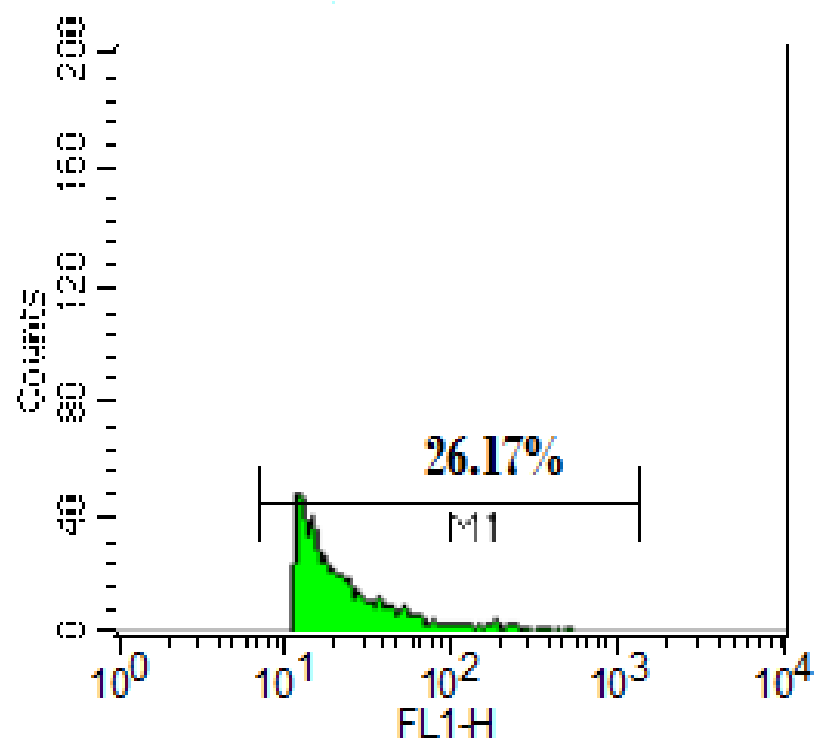

Fig.15.Group.1. control

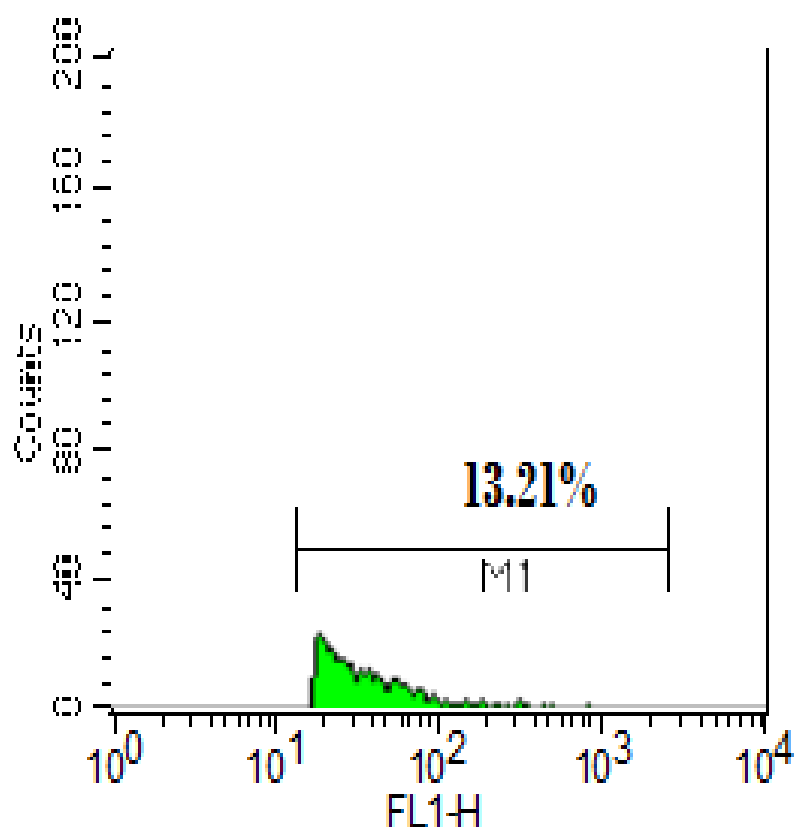

Fig.17.Group.3. DMBA

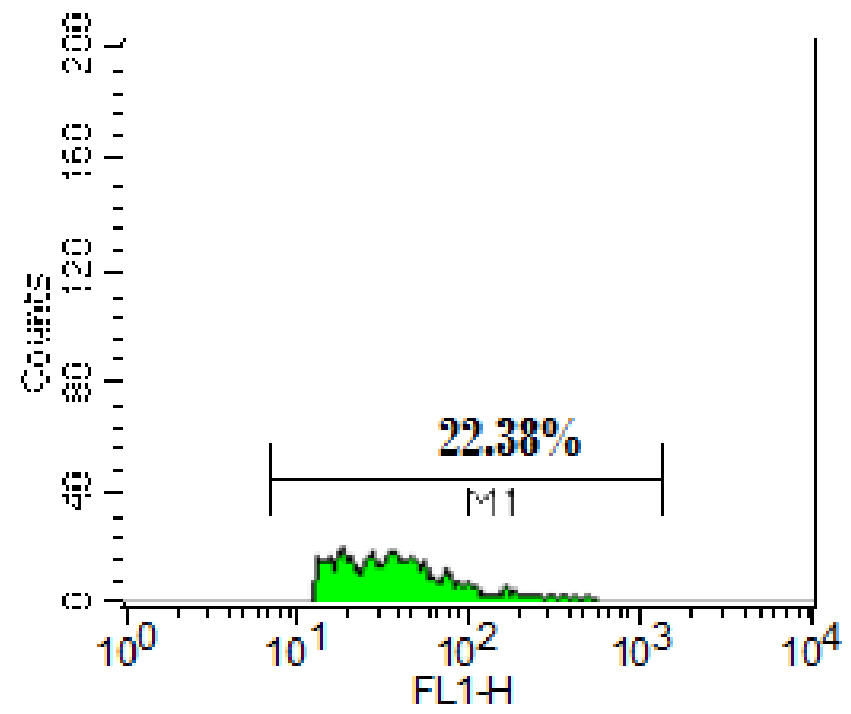

Fig.16.Complex

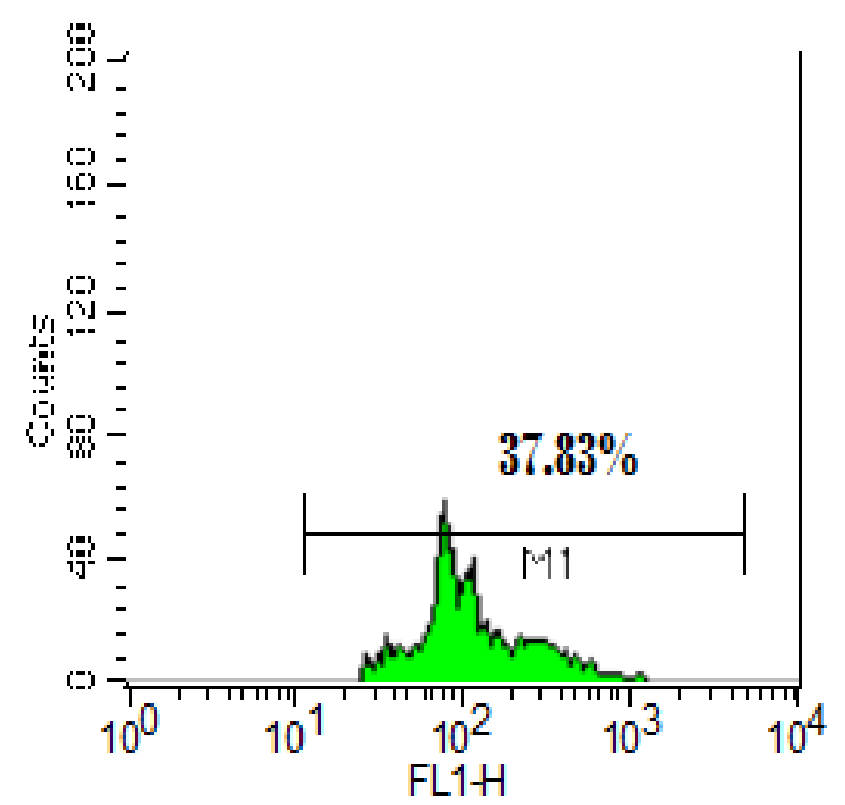

Fig.18.Group.4. DMBA+COMPLEX 


\section{5-Effect of complex on cas9 activity expressions on normal and DMBA rat}
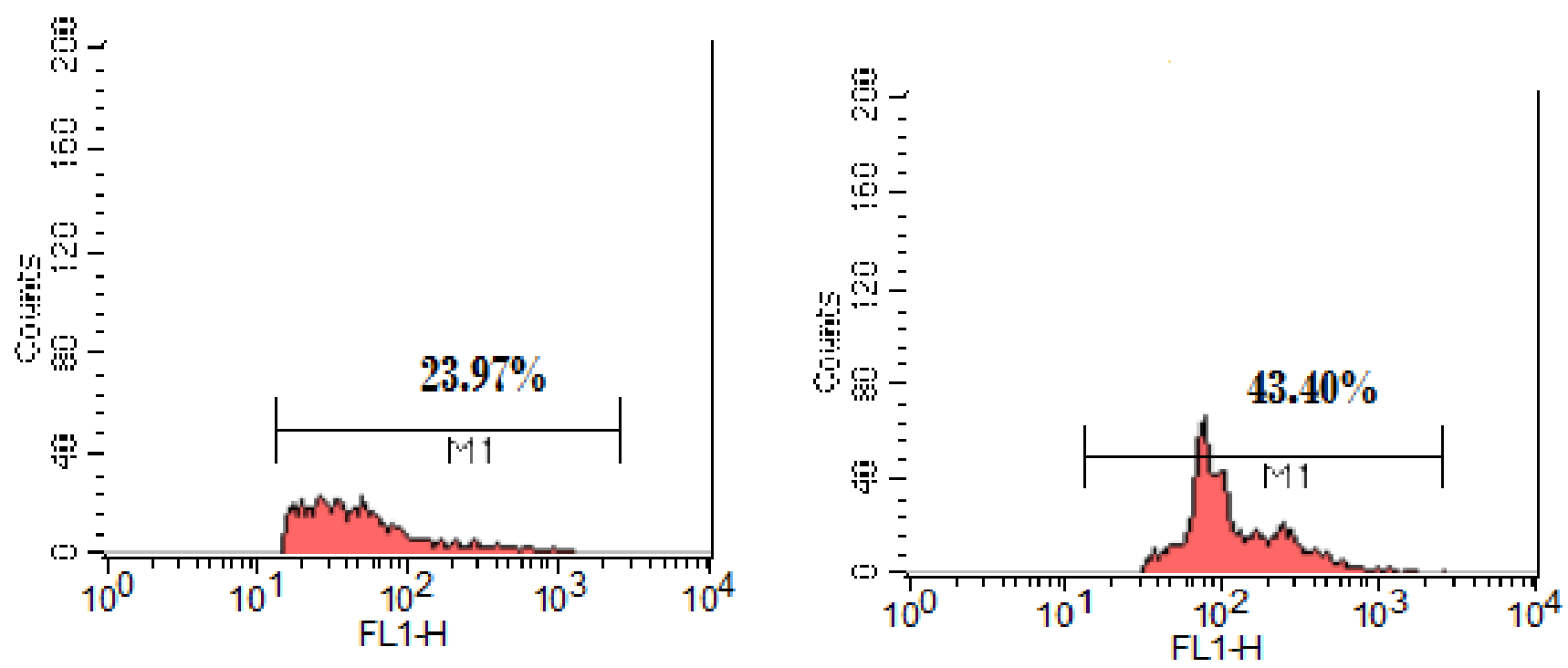

Fig.19.group.3. DMBA

Fig.20.group.4. DMBA+Complex

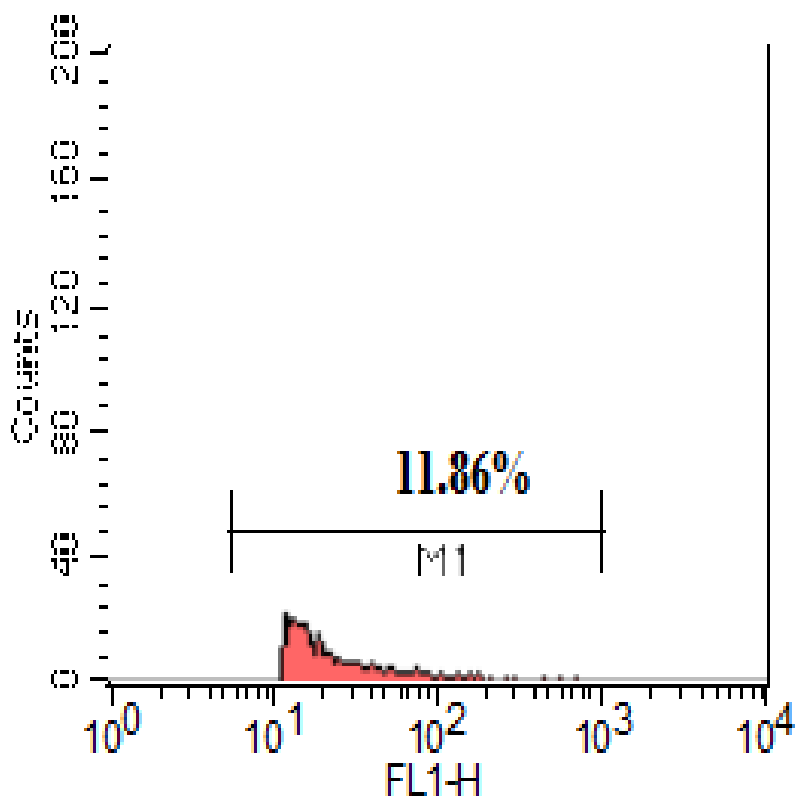

Fig.21.group.3. DMBA

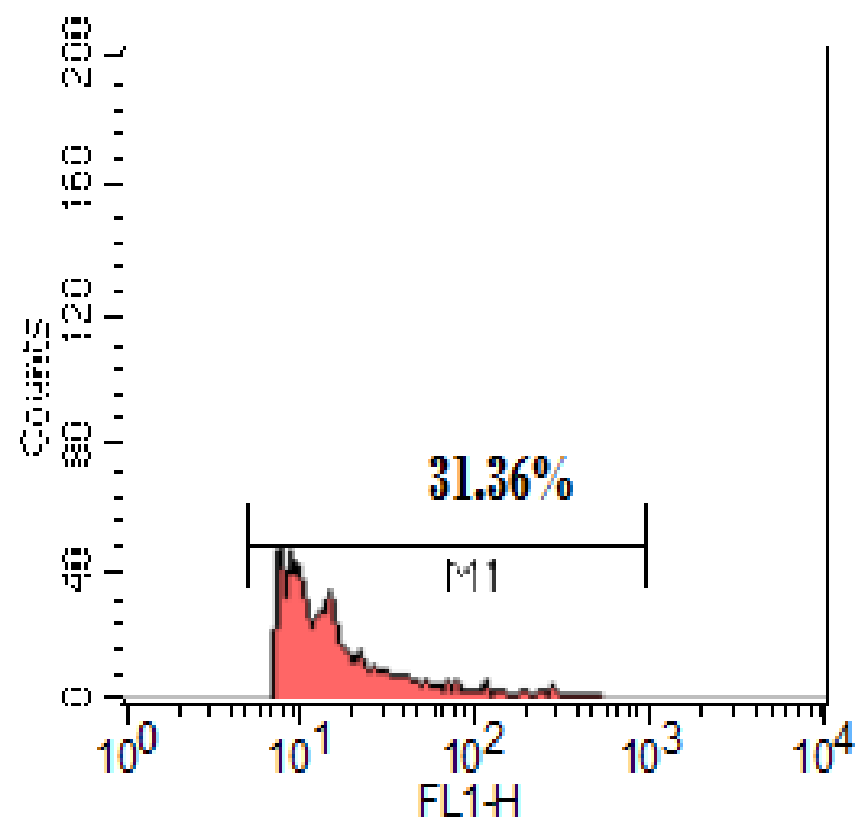

Fig.22.group.4. DMBA + Complex 
The potential anticancer effect of [Cadmium-N Acetyl cysteine] as novel drug therapy for mammary cancer induced by Di Methyl Benzene Anthanthrene in rats

6-Effect of complex on cell cycle expression on normal and DMBA rat.

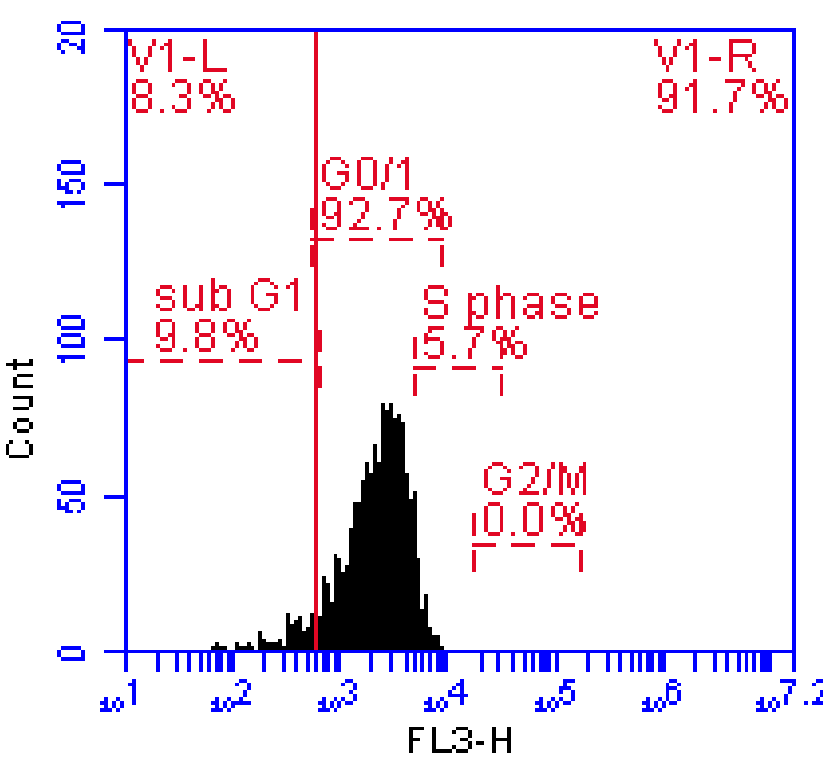

Fig.23.Group.1. control

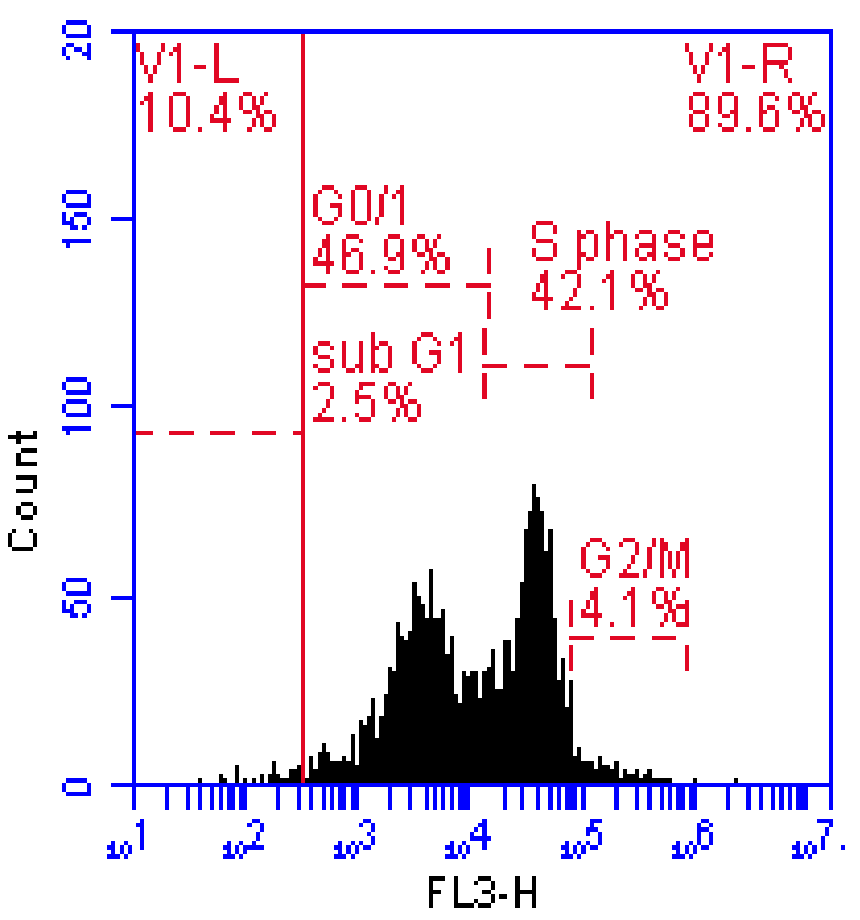

Fig.25.Group.3. DMBA

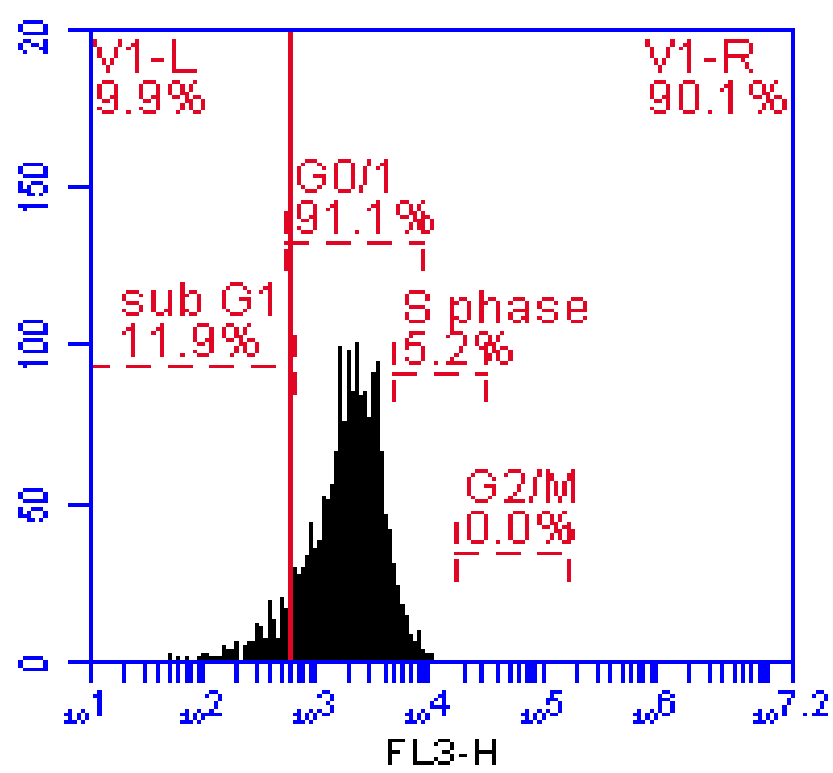

Fig.24.Group.2. complex

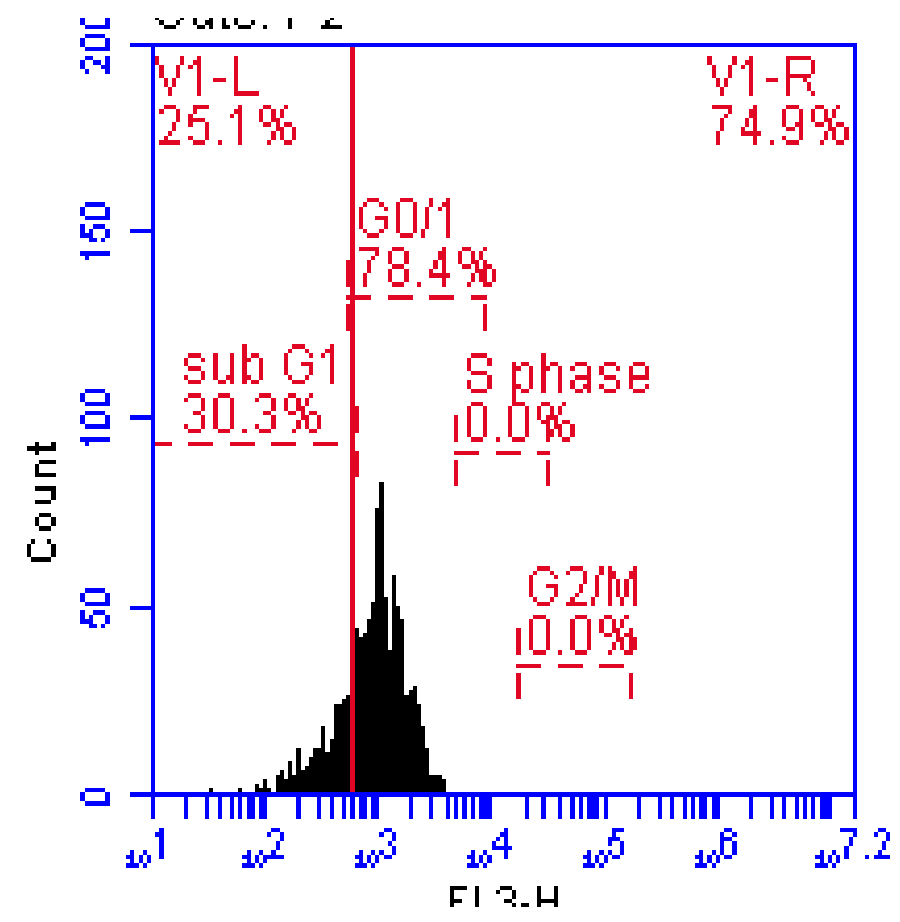

Fig.26.Group.4. DMBA + Complex 
Table.1. calculation of Ld50

\begin{tabular}{cl}
\hline Dose & Mortality \\
\hline $1000 \mathrm{mg}$ & Occur \\
\hline $500 \mathrm{mg}$ & Occur \\
\hline $250 \mathrm{mg}$ & Occur \\
\hline $125 \mathrm{mg}$ & Occur \\
\hline $72.5 \mathrm{mg}$ & Occur \\
\hline $36 \mathrm{mg}$ & Occur \\
\hline $18 \mathrm{mg}$ & Non \\
\hline $16 \mathrm{mg}$ & Non \\
\hline $12 \mathrm{mg}$ & Non \\
\hline
\end{tabular}

Table.2. calculation the mortality

\begin{tabular}{ll}
\hline Groups & Number of mortality \\
\hline $1^{\text {st }} .18 \mathrm{mg}$ & 2 \\
\hline $2^{\text {nd }} .16 \mathrm{mg}$ & 1 \\
\hline $3^{\text {rd }} .12 \mathrm{mg}$ & 0 \\
\hline
\end{tabular}

Table (3): Statistical analysis of (CD44.CYCLIN D1, P21 Cas-3. Cas-9 and cell cycle) expression genes in mammary tissue of female rat treated with complex after 12 weeks.

\begin{tabular}{lcccc}
\hline Groups & G0/1 & sub G1 & S & G2\M \\
\hline Control & $9.57 \pm 5.3$ & $9.500 \pm .522$ & $5.55 \pm 1.57$ & 0.000 \\
\hline Complex & $86.555 \pm .36$ & $10.083 \pm 2.025$ & $6.06 \pm 1.46$ & 0.000 \\
\hline DMBA & $68.991 \mathrm{a}, \mathrm{b} \pm 4.7$ & $6.493 \mathrm{~b} \pm .12$ & $36.3 \mathrm{a}, \mathrm{b} \pm 6.3$ & $2.55 \mathrm{~b}+1.6$ \\
\hline DMBA+COMPLEX & $86.0007 \mathrm{~b} \pm .2 .01$ & $8.8 \mathrm{a}, \mathrm{b} \pm 0.26$ & $9.66 \mathrm{a} \pm 8,3$ & 0.000 \\
\cline { 2 - 3 } & & & & \\
\hline
\end{tabular}

Table (4): repress cell

\begin{tabular}{llllll}
\hline Groups & CD44 & cyclinD1 & P21 & Cas-3 & Cas-9 \\
& & & & & \\
\hline Control & $31.5 \pm 0.5$ & $24.81 \pm 0.9$ & $27.801 \pm 0.2$ & $21.20, \pm 9$ & $23.419 \pm ., 28$ \\
\hline Complex & $31.79 \pm 1.2$ & $25.71 \pm 2.02$ & $8.40 \pm 2.68$ & $20.70 \pm 2.72$ & $24.005 \pm 2.35$ \\
\hline DMBA & $43.59 \mathrm{a}, \mathrm{b} \pm 12.4$ & $5.90 \mathrm{a}, \mathrm{b} \pm 22.3$ & $46.54 \mathrm{a}, \mathrm{b} \pm 19.9$ & $15.86 \mathrm{~b} \pm 6.06$ & $17.07 \mathrm{a} \pm 6.94$ \\
\hline DMBA+COMPLEX & $33.57 \mathrm{a} \pm 2.6$ & $30.24 \mathrm{a} \pm 6.20$ & $31.80 * \pm 5.069$ & $29.66 \mathrm{a}, \mathrm{b} \pm 9.8$ & $32.36 \mathrm{a}, \mathrm{b} \pm 10$ \\
\hline
\end{tabular}




\section{DISSCUSION}

Breast cancer is a major life-threatening concern among the malignancies encountered in females and ranks second as a cause of death. The discovery and development of new anticancer agents are crucial to prevent side effects and drug resistance problems caused by current available treatments.

Apoptosis is a programmed cell death which occurs due to the activation of certain evolutionarily conserved intracellular functions. While radio- and/or chemotherapeutic treatments are effective tools in treating certain cancers, a small population of cancer stem cells (CSC) can evade therapy which could be the reason for tumor recurrence and high rate of mortality. These CSC can bring the existence of new tumors and these are frequently found as multi-drug resistance (MDR) (Kawasaki et al., 2008).

NAC has been shown to block both DNA strand breakage and mutagenesis by DNAdamaging agents. Radioprotective effect of $N$ acetylcysteine in vitro using the induction of DNA breaks as end-point.CD44 is a trans membrane glycoprotein that has various functions in cell division, migration, adhesion, and signaling. CD44 normally binds to its primary ligand hyaluronic acid (HA). CD44 as an adhesion molecule is enables cell communication by cell-cell signal transduction (Gee et al., 2004). CD44 is highly expressed in many diseases. It has been found in cancerous, inflammatory, and autoimmunological diseases.

CD44 promotes homing of CSCs in many types of solid tumors, such as in breast and prostate cancers. The CD44 is a glycoprotein receptor that is activated by binding to its major ligand HA. This binding regulates stem cells homing. Breasts cancer cells show a remarkable heterogeneity and diversity among breast cancers and within tumors. Examining breast cancer cells with a technique known as Gene Expression Profiling indicates that cancer cells show a diverse population of cell subtypes.

CD44 and another surface protein, CD24, were both abnormally expressed in breast cancer cells, it is also important to investigate whether it has a role in chemotherapy resistance and relapsing of breast cancer (Olsson et al., 2011). Cyclin D1 is a cell-cycle regulator essential for G1 phase progression and a candidate protooncogene implicated in pathogenesis of several human tumor types, including breast carcinomas. The obtained results agree with (Leist and Jäättelä. 2001)who reported that overexpression / accumulation of the cyclin D1 protein in about half of the 170 primary breast carcinoma specimens analyzed by monoclonal antibody immunohistochemistry, indicating that the frequency of cyclin D1 abnormalities may be considerably higher than previously deduced from DNA amplification studies.

The activation of cysteine aspartate- specific proteases (caspases) is generally considered to be one of the key events in apoptosis pathway.

A classical apoptotic mode of cell death occurs only if the execution of death depends on caspase activity (Bartkova et al., 1994). Caspases can be broadly divided into the group of upstream initiator caspases including caspases -8 and -9 , and into the group of downstream executioner caspases including caspases-3(Cryns and Yuan 1998). 
Caspase-dependent pathway can further be subdivided into extrinsic or intrinsic pathway, depending on the role of caspase- 8 or caspase- 9 , respectively. It seems that apoptotic signaling elicited by complex might be related to the mitochondrial pathway, thus caspase-9 and caspase-3 activation was studied during the induction of apoptosis.

We observed activation of caspase- 9 and caspase-3 after treatment of complex Inhibitors specific to these caspases could restore the cells from cell death. From these observations, it may be suggested that once activated, this initiator caspase (caspase-9) can cleave and stimulate caspase-3 and other effector caspases, thereby turning on a cascade of events exp cv editing DNA fragmentation and cell death.

The significance of cell cycle mediators in breast carcinogenesis is currently well established. Specifically, deregulation of crucial genes that control cell cycle checkpoints has been noted in various breast carcinomas (Malumbres and Barbacid 2009). Moreover, dysfunction or loss of these genes can also mediate resistance to chemotherapeutic agents.

Dysregulation of the cell cycle underlies the uncontrolled cell proliferation that characterizes cancer. The cell cycle machinery can be regarded as a final and critical step in growth control downstream of complex and redundant oncogenic signaling networks and therefore a potentially attractive intervention points for cancer diagnostics and therapeutics.

\section{REFERENCES:}

Bartkova J, Lukas J, Müller H, Lützhøft D, Strauss M, Bartek J.(1994).Cyclin D1 protein expression and function in human breast cancer. Int $\mathbf{J}$ Cancer. May 1;57(3):353-61.

Brama M, Gnessi L, Basciani S, Cerulli N, Politi L, Spera G, Mariani S, Cherubini S,
Scotto d'Abusco A, Scandurra R, Migliaccio S.Format: Abstract .(2007). Cadmium induces mitogenic signaling in breast cancer cell by an E Ralphdependent mechanism. Mol Cell Endocrinol;264(1-2):102-8.

Carleton, H. M. Harry Montgomerie. (1980). Histological technique, 5th ed. / by R.A.B. Drury, E.A. Wallington. Description Oxford; New York: Oxford University Press, vi, 520 p.: ill.; $24 \mathrm{~cm}$. ISBN 0192613103.

Cohen sethM(2007).New approaches for medicinal applications of bioinorganic chemistry . Current Opinion in Chemical Biology.Volume 11, Issue 2, Pages 115120.

Cryns V, Yuan J. (1998). Proteases to die for.Genes Dev.;12(11):1551-70. doi: $10.1101 / \mathrm{gad} .12 .11 .1551$.

Frezza M, Hindo S, Chen D, Davenport A, Schmitt S, Tomco D, Dou QP .(2010). Novel metals and metal complexes as platforms for cancer therapy. Curr Pharm Des. 16(16):1813-25.

Gee K, Kryworuchko M, Kumar A. (2004). Recent advances in the regulation of CD44 expression and its role in inflammation and autoimmune diseases. Arch ImmunolTherExp (Warsz) ;52:1326.

Haas KL, Franz KJ .(2009). Application of metal coordination chemistry to explore and manipulate cell biology.Chem Rev.;109(10):4921-60.

Jemal A, Bray F, Center MM, Ferlay J, Ward E, Forman D.(2011). Global cancer statistics.CA Cancer J Clin.:69-90. doi: 10.3322/caac.20107. 
Kawasaki BT, Hurt EM, Mistree T, Farrar WL. (2008). Targeting cancer stem cells with phytochemicals. MolInterv; 8:1174-84. doi: $10.1124 / \mathrm{mi} .8 .4 .9$

Leist M, Jäättelä M. (2001). Four deaths and a funeral: from caspases to alternative mechanisms. Nat Rev Mol Cell Bol;2(8):589-98.

Malumbres M, Barbacid M. (2009). Cell cycle, CDKs and cancer: a changing paradigm. Nat Rev Cancer ;9(3):153-66. pmid:19238148.

Milton, O., H. R. Pollio, and J. A. Eison. (2011). Making Sense of College Grades. San Francisco: Jossey-Bass.

Miyata M, Furukawa M, Takahashi K, Gonzalez FJ, Yamazoe Y.Jpn J Pharmacol.(2001). Mechanism of 7,12dimethylbenz[a]anthracene-induced immunotoxicity: role of metabolic activation at the target organ.;86(3):3029

Olsson E, Honeth G, Bendahl PO, Saal LH, Gruvberger-Saal $S$, Ringnér $M$, et al. (2011). CD44 isoforms are heterogeneously expressed in breast cancer and correlate with tumor subtypes and cancer stem cell markers. BMC Cancer; 11:418.

SimonSimon Paul Fricker.(2007).Metal based drugs: from serendipity to designDalton Trans. 4903-4917 DOI: 10.1039/B705551J

Zhukalin $\mathrm{M}^{1}$, Blanksma MK, Silva TD, Suyehira SW, Harvey WA, Heggland SJ, Craig PR. (2007). Characterization and in vitro cytotoxicity testing of ethanolaminederived cadmium chelating agents.Biometals. 20(1):61-72. 